\title{
A multidimensional scaling analysis of judged similarity of complex forms from two task situations $* \dagger$
}

\author{
LARRY G. RICHARDS \\ University of Virginia, Charlottesville, Virginia 22901
}

Ss provided judgments of pairwise stimulus similarities for 21 12-turn random forms in two experimental tasks: a scaling task, involving a variant of the method of graded dichotomies, and a sorting task, which simply required Ss to categorize the forms. The grouped data from both tasks, when analyzed using nonmetric multidimensional scaling techniques, yielded five-dimensional configurations with euclidean distances. The correspondence of these two spaces, assessed using canonical correlations, was extremely good. The psychological dimensions derived from both tasks were related to two sets of physical measures on the forms: the factor space suggested by Brown and Owen and a set of more basic physical measures. Physical cues of greatest importance involved size, dispersion, angularity, and rotation measures. The value of the tasks and the utility of the Brown and Owen measures were discussed.

Attempts to explore the psychophysics of form perception have been hampered by the lack of an adequate physical characterization of form. A recent move toward providing such a characterization was made by Brown and Owen (1967), who were concerned with finding a physical space appropriate for describing random forms generated by Method 1 of Attneave and Arnoult (1956). Two hundred shapes were constructed at each of five complexity (sidedness) levels: $4,8,12,16$, and 20 sides. $A$ survey of prior experimental work turned up 130 measures which had previously been employed to specify physical aspects of form. Preliminary screening to eliminate perfect or extremely high correlations reduced the number of measures to 80 .

Values on these 80 measures were obtained for each of the 1,000 random shapes. A principal components analysis was performed on the correlations computed between measures over shapes for each complexity level. Both orthogonal and oblique rotations were performed on the 12 components retained in each analysis, and component scores were computed for each shape. Twelve

*The work reported here was carried out while the author was a USPHS trainee in measurement psychology at the University of Illinois at Urbana-Champaign. The author wishes to acknowledge the encouragement, assistance, and support of his thesis advisor, Dr. Ledy ard R. Tucker. Other members of the thesis committee were Drs. Hake, Osgood, Batchelder, N. Wiggins, Burkbolder, and Hohn, and their guidance was greatly appreciated.

TThe author wishes to thank D. R. Brown of Purdue University for providing line drawings and measures on the 200 12-turn shapes constructed by Brown and Owen (1967). components accounted for $87 \%, 81 \%$, $78 \%, 75 \%$, and $74 \%$ of the variance for 4-, 8-, 12-, 16-, and 20-turn shapes, respectively. As complexity increased, so did the number of components necessary to account for a given proportion of the variance. The five major components appeared to be the same at all complexity levels. The first component was called "dispersion" and reflected the degree to which the area of the shape was distributed away from its center of gravity. The second component was interpreted as "jaggedness." Area skewness along the $y$ - and $x$-axes constituted Components 3 and 4, while Component 5 reflected the "directionality" or rotation of the shape.

Brown and Owen proposed their physical characterization of the random forms as a basis for further work on the psychophysical investigation of form perception and suggested an iterative process to determine the psychologically relevant aspects of random forms. In the present investigation, a set of stimulus forms was selected from the 200 12-turn shapes of Brown and Owen. Each form was characterized by its value on all 12 Brown and Owen dimensions, although the forms were selected as markers for the five major Brown and Owen dimensions. In addition, 17 more traditional physical measurements were made on each form. Thus, two physical characterizations of the forms involving 29 measures were available.

The techniques of multidimensional scaling were used to extract the psychological dimensions of visual form from Ss' judgments about the similarity of pairs of forms. Two methods of gathering data were used: a scaling task, which required Ss to make judgments about all pairwise combinations of the forms, and a sorting task, which simply required Ss to sort the individual forms into categories. Data from both tasks were processed using the MDSCAL and TORSCA programs. MDSCAL embodies an approach to scaling developed by Shepard $(1962 a, b)$ and extended and refined by Kruskal (1964a, b). TORSCA was developed by Young (1968) from an earlier conception of Torgerson and Meuser (1962). The TORSCA program involves a preliminary factor analysis of the data to find the initial configuration to be processed by the nonmetric algorithm.

Correlational techniques were then used to assess the extent to which the physical dimensions of the stimuli corresponded to the psychological dimensions obtained from scaling and to explore the degree of agreement obtained by scaling the data from the two tasks.

\section{METHOD \\ Subjects}

Forty-nine persons served as Ss for this experiment: 46 were University of Illinois undergraduates, 1 was a graduate student, and 2 were wives of graduate students. Twenty-seven of the students satisfied course requirements by participating; the other 22 Ss were paid for their services.

\section{Stimuli}

Twenty-one 12-tum random forms, selected from the set generated by Brown and Owen (1967), were used in this study. These forms were selected as markers on the five most prominent Brown and Owen (B \& O) dimensions, and component scores for each form on all $12 \mathrm{~B} \& \mathrm{O}$ dimensions were obtained. In addition, 17 basic physical measures were taken on each form. Brown and Owen's components had been derived from a large number of such basic measures. These 17 measures are defined as follows:

(1) $P$-the length of the perimeter as measured in millimeters; the sum of all the side lengths.

(2) A-the area enclosed by the perimeter of the form as measured in square millimeters.

(3) $\mathrm{P}^{2} / \mathrm{A}$-the ratio of the square of the perimeter to the area. Attneave (1957) proposed this as a measure of dispersion or noncompactness.

(4) $\mathrm{VE} / \mathrm{HE}$ - the ratio of vertical to horizontal extent of the form. This measure was used by Brown and Andrews (1968) as a measure of rotation.

(5) VIA-the variance of the interior angles of the form. The angles were measured in degrees. 
Table 1

Varimax Rotated Matrix of Factors of the Bacic Physical Mencures

\begin{tabular}{|c|c|c|c|c|c|}
\hline \multirow{2}{*}{$\begin{array}{c}\text { Basic } \\
\text { Physical } \\
\text { Measures }\end{array}$} & \multicolumn{5}{|c|}{ Factors } \\
\hline & 1 & 2 & 3 & 4 & 5 \\
\hline $\mathbf{P}$ & .827 & .156 & .010 &,- 161 & .410 \\
\hline $\mathbf{A}$ & -.146 & -.190 & .032 & -.200 & .739 \\
\hline $\mathbf{P}^{2} / \mathbf{A}$ & .741 & .227 & .049 & .048 & -.205 \\
\hline VE/HE & -.005 & .094 & 1.037 & -.147 & .063 \\
\hline VIA & .837 & -.072 & .002 & -.010 & -.160 \\
\hline MDIA & .828 & -.105 & .010 & -.128 & -.045 \\
\hline VDIA & .486 & -.383 & -.051 & -.130 & .022 \\
\hline MSA & -.946 & .282 & .012 & -.069 & .140 \\
\hline VSA & -.062 & .877 & .135 & -.208 & .000 \\
\hline MDSA & .029 & .921 & .064 & .058 & -.012 \\
\hline VDSA & -.110 & .769 & .025 & .118 & -.167 \\
\hline ROTS & .001 & -.317 & .261 & -.674 & -.163 \\
\hline $\mathbf{H E}$ & .000 & -.134 & -.819 & .149 & .269 \\
\hline $\mathbf{V E}$ & .025 & .020 & .795 & -.145 & .431 \\
\hline LGE & -.111 & .009 & .032 & .458 & .615 \\
\hline SBRT & -.061 & -.004 & -.240 & .591 & -.067 \\
\hline ROTO & -.077 & -.166 & .018 & .935 & -.106 \\
\hline
\end{tabular}

(6) MDIA-the mean of the differences between successive interior angles, measured in degrees.

(7) VDIA - the variance of the differences between successive interior angles.

(8) MSA-the mean of the angles in the form, when angles are measured so that the value obtained is less than 180 deg. Thus, for this measure (as well as the next three), either the interior or the corresponding exterior angle was measured, depending upon which was amaller.

(9) VSA - the variance of the angles measured as values less than $180 \mathrm{deg}$.

(10) MDSA-the mean of the differences between successive angles when angles are measured as in (8).

(11) VDSA-the variance of the differences between successive angles when angles are measured as in (8).

(12) ROTS-rotation measured in degrees by the deviation of the line of greatest extent from the vertical in either a clockwise or counterclockwise direction.

(13) ROTO-rotation measured in degrees by the deviation of the line of greatest extent from the vertical in a clockwise direction. This measure is similar to what Stenson (1966) called orientation.

(14) HE-the horizontal extent of the form as measured in millimeters.

(15) VE-the vertical extent of the form in millimeters.

(16) LGE-the length, in millimeters, of the line connecting the two most distant points on the perimeter of the form.

(17) SBRT-a subjective measure of rotation. The orientation of the form was judged by $E$ in terms of LGE and measured from the vertical in degrees.

Since there were substantial correlations among some of the basic physical measures, a factor analysis was performed to clarify those relationships. A principal components analysis of the measure by measure correlation matrix was done, followed by a Varimax rotation. The first five components all had eigenvalues greater than one, and there was a clear break in the plot of the eigenvalues between the fifth and sixth root. These five components accounted for $82.2 \%$ of the variance. The loadings of the various measures on these components are presented in Table 1. Component 1 is marked by dispersion measures (P, $\mathrm{P}^{2}$ (A) and by some angle measures (VIA, MDIA, MSA). Component 2 is angularity as measured by VSA, MDSA, and VDSA. Component 3 involves the ratio of vertical to horizontal extent. Component 4 is rotation and Component 5 is size ( $A$, LGE). Components 1,2 , and 4 from this analysis resemble B \& O Factors 1 , 2 , and 5 .

\section{Scaling Task}

A set of 231 stimulus cards containing all possible pairings of the 21 forms (including the 21 identity pairs) were presented to Ss. Each S partitioned the set of 231 cards into eight ordered categories on the basis of the relative similarity of the pair of forms on each card. The scaling task was a variation of the method of graded dichotomies (see Richards, 1971). The numbers 0-7 were assigned to the piles containing cards whose members were judged most similar through least similar, respectively.

Sorting Task

In the sorting task, Ss were asked to place the 21 individual forms into classes or categories. The Ss were free to impose any rule, criterion, or basis for categorization that seemed natural or reasonable to them. There were to be at least two, but not more than eight, categories with any number of forms in each. Upon completing his sort, $\mathrm{S}$ was asked to state his basis for categorization.

\section{RESULTS}

Analysis of the Scaling Data:

The Average Perceptual Space

Mean judgments of interstimulus similarity, averaged over the $49 \mathrm{Ss}$, were computed for each of the 231 stimulus pairs. These averaged judgments were then input to nonmetric multidimensional scaling routines. Kruskal's MDSCAL III was used for most of the scaling, then MDSCAL $V$ and TORSCA were later used to verify and extend these results. MDSCAL III was used to explore configurations varying in dimensionality from 10 to 1 , using both the euclidean $(R=2.0)$ and the city block $(R=1.0)$ metrics. MDSCAL $V$ allows a maximum dimensionality of only 6 , so that program and TORSCA were used to explore dimensionalities from 6 to 1 . More than 25 runs were done with various starting configurations to assure that global, rather than local, minima resulted from the analyses. For the $\mathbf{R}=2.0$ configurations, most of the runs converged upon the same final stress values, and these were the minimum values obtained in any runs. The $R=1.0$ solutions, however, were problematic. Here, the different runs did not generally terminate in the same minimum stress values at any given dimensionality. Stress values for $R=1.0$ runs usually exceeded those from $R=2.0$ runs. But with 4,5 , and 6 dimensions, if the corresponding $R=$ 2.0 solution was entered as the starting configuration for the $R=1.0$ analysis, stress values were obtained equal to those from the euclidean metric. No other starting configurations were found which yielded these low stress values for $R=1.0$ metrics. Thus, although the $R=2.0$ solutions seem to represent global minima reachable from many starting configurations, the best $R=1.0$ solutions were obtained from only one starting configuration. Further, there is no assurance that even these are true minima.

The best stress values for each dimensionality for both the city block and euclidean metrics are shown in Table 2. In general, these stress values represent minima achieved on different runs; that is, the starting configuration giving the lowest stress in $\mathbf{N}$ dimensions is not necessarily the one that yielded the lowest stress in N-1 dimensions. Table 2 contains stress values from both the MDSCAL and TORSCA analyses and the TORSCA goodness of fit (FIT) index developed by Young (1968). All stress values reported from MDSCAL represent runs which were terminated 
because minimum stress was achieved. TORSCA runs were terminated either for that reason or because continued iteration failed to noticeably improve stress levels. Thus, for $R=1.0$, in the six-dimensional solution, 100 iterations yielded a stress of .066 and FIT $=.9989$, while 150 iterations gave a stress of .065 and FIT $=.99895$. So the 150-iteration solution was accepted as final, despite the fact that the program had failed to terminate the run.

Configurations ranging from four to seven dimensions seemed plausible in terms of stress levels and the distribution of stress over the various dimensionalities. Stenson and Knoll (1969) have provided sets of stress values obtained by scaling random input data. These stress values represent the null hypothesis that a set of similarity data is random. Table 2 includes a lower bound for the acceptance region implied by this null hypothesis. These numbers are based on values extracted from Stenson and Knoll's Fig. 1 (p. 123) and on their conservative decision rule. Using this criterion, six or more dimensions can be justified for this data. Another criterion for deciding when a sufficient number of dimensions has been included is provided by Young (1968). He has found that FIT values from the TORSCA program must be in excess of .999 before a sufficient fit has been achieved. For the $\mathbf{R}=\mathbf{2 . 0}$ metric, this FIT value is first achieved with five dimensions. More than six dimensions would be required with an $R=1.0$ metric. Thus, several kinds of considerations imply the need for at least five dimensions to account for this data.

Even though the $R=1.0 \mathrm{MDSCAL}$ solutions in 4,5 , and 6 dimensions gave stress values close or equal to their euclidean counterparts, the corresponding configurations were not as interpretable as the euclidean solutions. The same basic physical measures were related to the city block and the euclidean configurations, but the patterns of relationship were clearer and made more sense in the euclidean case. The patterns of relation in the city block space suggest that a rotation of axes might improve the fit of the basic physical measures, but, of course, such rotation is impossible in $R=1.0$ space. Rotation does not leave city block distances invariant.

The six- and seven-dimensional euclidean solutions involved dimensions which could not be interpreted in terms of the measures included in this study. The empirically best solution was the five-dimensional euclidean configuration. A Varimax rotation of this configuration was

Table 2

Best Stress Values for Scaling Data as a Function of Metric and Dimensionality Dimensionality

\begin{tabular}{|c|c|c|c|c|c|c|}
\hline \multirow[b]{2}{*}{$\mathrm{R}=1.0$} & & & & & & \\
\hline & 1 & $\mathbf{2}$ & 3 & 4 & 5 & 6 \\
\hline $\begin{array}{c}\text { MDSCAL-Stress } \\
\text { TORSCA-Stress } \\
\text {-Fit }\end{array}$ & $\begin{array}{l}.392 \\
.385 \\
.961\end{array}$ & $\begin{array}{l}.234 \\
.220 \\
.988\end{array}$ & $\begin{array}{l}.154 \\
.157 \\
.994\end{array}$ & $\begin{array}{l}.098 \\
.114 \\
.997\end{array}$ & $\begin{array}{l}.071 \\
.081 \\
.998\end{array}$ & $\begin{array}{l}.058 \\
.070 \\
.999\end{array}$ \\
\hline \multicolumn{7}{|l|}{$R=2.0$} \\
\hline $\begin{array}{c}\text { MDSCAL-Stress } \\
\text { TORSCA-Stress } \\
\text {-Fit }\end{array}$ & $\begin{array}{l}.374 \\
.389 \\
.961\end{array}$ & $\begin{array}{l}.217 \\
.211 \\
.989\end{array}$ & $\begin{array}{l}.138 \\
.139 \\
.956\end{array}$ & $\begin{array}{l}.098 \\
.100 \\
.998\end{array}$ & $\begin{array}{l}.071 \\
.072 \\
.999\end{array}$ & $\begin{array}{l}.053 \\
.056 \\
.999\end{array}$ \\
\hline $\begin{array}{l}\text { Stenson and Knoll } \\
\text { Lower Bound }\end{array}$ & .46 & .27 & .17 & .15 & .09 & .07 \\
\hline
\end{tabular}

Table 3

Correlations of the Psychological Dimemsions of the Average Perceptual Space With the Brown and Owen Mearares

\begin{tabular}{|c|c|c|c|c|c|c|c|c|c|c|}
\hline \multirow{3}{*}{$\begin{array}{l}\text { Brown } \\
\text { and } \\
\text { Owen } \\
\text { Measures }\end{array}$} & \multicolumn{10}{|c|}{ Paychological Dimensions } \\
\hline & \multicolumn{5}{|c|}{ Unrotated } & \multicolumn{5}{|c|}{ Varimax Rotated } \\
\hline & P1 & P2 & $\mathbf{P 3}$ & $\mathbf{P 4}$ & P5 & $\mathbf{V 1}$ & $\mathbf{V 2}$ & $\mathbf{V 3}$ & V4 & VB \\
\hline $\begin{array}{l}\text { I } \\
\text { II } \\
\text { III } \\
\text { IV } \\
\text { V } \\
\text { VI } \\
\text { VII } \\
\text { VIII } \\
\mathbf{I X} \\
\mathbf{X} \\
\mathbf{X I} \\
\mathbf{X I I}\end{array}$ & $\begin{array}{r}-.73 \\
.14 \\
.02 \\
.37 \\
-.15 \\
-.33 \\
-.42 \\
-.20 \\
-.38 \\
.12 \\
.08 \\
.38\end{array}$ & $\begin{array}{r}-.12 \\
-.03 \\
-.14 \\
-.12 \\
.36 \\
.22 \\
-.26 \\
-.51 \\
-.43 \\
.41 \\
.41 \\
-.44\end{array}$ & $\begin{array}{r}-.10 \\
-.20 \\
.08 \\
.23 \\
-.04 \\
.34 \\
.12 \\
-.58 \\
-.04 \\
.00 \\
.01 \\
.17\end{array}$ & $\begin{array}{r}.67 \\
.04 \\
-.24 \\
.04 \\
-.47 \\
-.10 \\
-.14 \\
-.03 \\
.04 \\
.17 \\
.19 \\
-.15\end{array}$ & $\begin{array}{r}-.04 \\
-.29 \\
. .33 \\
-.11 \\
-.34 \\
-.03 \\
-.47 \\
-.29 \\
-.55 \\
. .26 \\
-.18 \\
.06\end{array}$ & $\begin{array}{r}.23 \\
.11 \\
-.13 \\
-.24 \\
.52 \\
.18 \\
.54 \\
.43 \\
.49 \\
-.28 \\
-.01 \\
-. .22\end{array}$ & $\begin{array}{r}-.84 \\
.12 \\
.13 \\
.16 \\
.21 \\
-.25 \\
-.29 \\
-.01 \\
-.01 \\
.03 \\
-.03 \\
.23\end{array}$ & $\begin{array}{r}.15 \\
-.18 \\
.34 \\
-.18 \\
-.24 \\
-.09 \\
.03 \\
.36 \\
.04 \\
-.18 \\
-.46 \\
.21\end{array}$ & $\begin{array}{r}-.00 \\
-.32 \\
.21 \\
-.28 \\
.21 \\
.34 \\
-.22 \\
-.49 \\
-.49 \\
.31 \\
.03 \\
.29\end{array}$ & $\begin{array}{r}.41 \\
.10 \\
-.17 \\
-.24 \\
-.19 \\
-.24 \\
-.28 \\
.28 \\
-.12 \\
.23 \\
.116 \\
-.34\end{array}$ \\
\hline
\end{tabular}

Table 4

Correlations of the Prycholocieal Dimensions of the Average Perceptual Space With the Basic Phyteal Measures

Poychological Dimensions

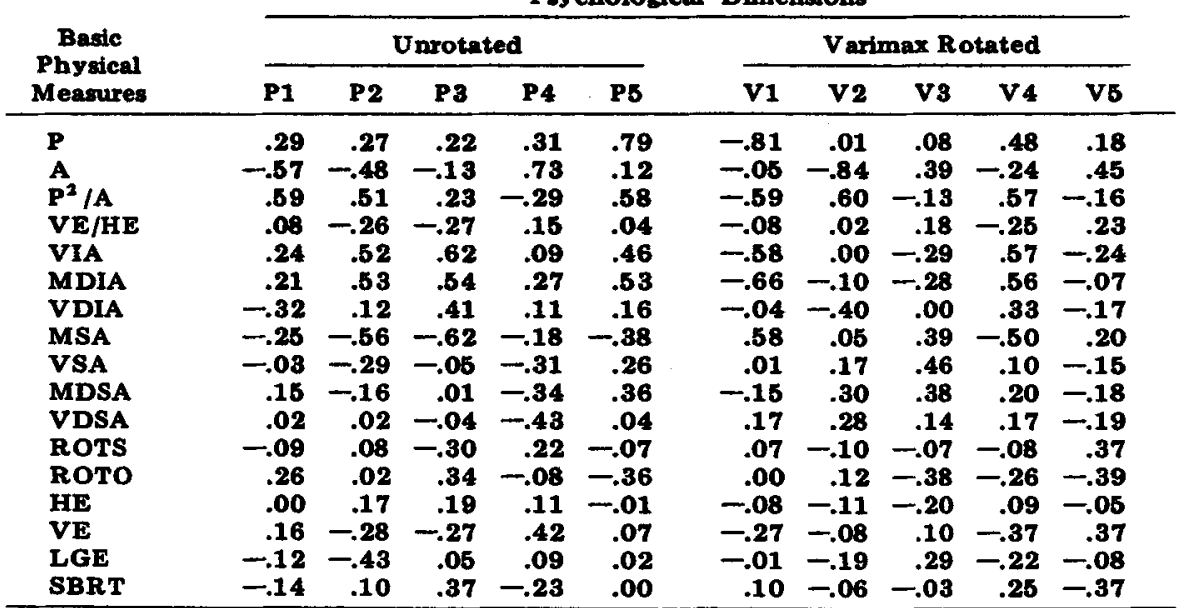

performed. Thus, two models of the average perceptual space were obtained: the configuration produced by MDSCAL ( $P$ configuration) and the Varimax rotation thereof (V configuration). The TORSCA configuration in five-dimensional euclidean space did not differ substantially from the MDSCAL solution either in its relation to the physical measures or in stress.

\section{Relations of the Scaling Solutions} to Physical Measures

Simple product moment correlation coefficients relating the $12 \mathrm{~B} \& \mathrm{O}$ measures to the $P$ configuration are displayed in Table 3. P1 correlated highly with $B$ \& $O$ I-the compactness-dispersion dimension. P2 and $\mathrm{P3}$ are both related to $\mathrm{B} \& \mathrm{O}$ VIII but differ in their pattern of relations to the other B \& O measures. P4 also 
Table 5

Multiple Regression Analysis Predicting Psychological Dimentions of the Average Perceptual Space from the $B$ and $O$ Dimensions

\begin{tabular}{|c|c|c|c|c|c|}
\hline & \multicolumn{5}{|c|}{ Standardized Regression Coefficients } \\
\hline & $\mathbf{P 1}$ & P2 & P3 & $\mathbf{P 4}$ & P5 \\
\hline \multirow[t]{3}{*}{$\begin{array}{l}B \text { and } O \text { I } \\
B \text { and } O \text { II } \\
B \text { and } O \text { III } \\
B \text { and } O \text { IV } \\
B \text { and } O V\end{array}$} & $\begin{array}{r}-.7769 \\
.2942 \\
-.0889 \\
.0422 \\
-.1460\end{array}$ & $\begin{array}{r}-.1935 \\
-.0314 \\
-.1830 \\
-.1138 \\
.3463\end{array}$ & $\begin{array}{r}.0445 \\
-.2015 \\
.0835 \\
.2424 \\
.0272\end{array}$ & $\begin{array}{r}.6495 \\
-.0203 \\
-.1293 \\
.2124 \\
-.4289\end{array}$ & $\begin{array}{r}-.0329 \\
-.2690 \\
.3598 \\
-.2379 \\
-.3845\end{array}$ \\
\hline & .8035 & $\begin{array}{l}\text { Multiple } \\
.4335\end{array}$ & $\begin{array}{c}\text { Correlation } \\
.3129\end{array}$ & $\begin{array}{r}\text { Coetficient } \\
.7828\end{array}$ & .5969 \\
\hline & .3551 & $\begin{array}{l}\text { Standare } \\
.4107\end{array}$ & $\begin{array}{c}\text { Error of } \\
.4369\end{array}$ & $\begin{array}{r}\text { Estimate } \\
.3430\end{array}$ & .4546 \\
\hline
\end{tabular}

involves dispersion ( $B \& O$ I) and has a marginal correlation with $B$ \& $O V$ (rotation). P5 relates strongly to $B$ \& $O$ IX and moderately to B \& O VII.

Only two of the five dimensions of the $V$ space have strong correlations with the $B$ \& $O$ measures. VI is indexed by $B$ \& $O V$ (rotation) and VII, and also is moderately correlated with B \& $O$ IX. V2 has an extremely high correlation with $B$ \& $O$ I (dispersion) and low correlations with all the other $B$ \& $O$ measures. V3 relates marginally to $\mathrm{B} \& \mathrm{O} \mathrm{XI}$, as does V4 to both B \& O VII and IX.

In terms of the basic physical measures, the $P$ dimensions are all readily interpretable. As may be seen in Table 4, P1 is a size-dispersion dimension, being related to $A$ and $\mathrm{P}^{2}$ /A. $\mathrm{P3}$ is an angularity dimension indexed by VIA, MDIA, and MSA. P2 combines size dispersion with angularity and seems to represent a conglomerate of P1 and P3. P4 is clearly area, and P5 is compactness dispersion (indexed by $P$ and $P^{2} / A$ ). Perceptually separable aspects of size and dispersion are evident in the three dimensions P1, P4, and P5.

In the Varimax rotation of the average perceptual space, the interpretations of specific dimensions are altered, but the same physical variables are important. V1 combines a large dispersion influence with angularity. $\mathrm{V} 4$ is similar to $\mathrm{V} 1$, involving angulurity, but with less influence of dispersion. V2 is size dispersion, having a very high correlation with area. The $P$ configuration is clearly preferable to the $V$ configuration in the way it relates to both sets of physical measures. All five $P$ dimentions are interpretable in both cases.

To examine the predictive utility of the five major Brown and Owen dimensions, a multiple regression analysis was performed with these physical measures as predictors and each unrotated psychological dimension of the average perceptual space in turn as the criterion. The results appear in Table 5 . Significant multiple $\mathrm{Rs}$ were found in only two cases. Sixty-four percent of the variance in $P 1$ is predictable from a linear combination of the five major B \& O measures. B \& O I, compactness dispersion, contributes most strongly to the prediction. Sixty-one percent of the variance in $\mathrm{P} 4$ is predicted by a regression equation, with $B$ \& $O I$ and $V$ (rotation) having the most influence. In addition, $36 \%$ of the variance in $\mathrm{P5}$ is accounted for by these physical measures, with B \& O III ( $y$-axis asymmetry) and $V$ being most important.

When the full set of 12 B \& 0 measures was used to predict the various $P$ dimensions, the expected improvement in prediction resulted. The multiple correlation coefficients, as shown in Table 6, are large, as would be expected given 12 eseentially orthogonal predictors. What is interesting is the pattern of the standardized regression coefficients and thus the relative importance of the $B$ \& $O$ measures. $P 1$ is influenced equally by both B \& O I and VII. P2 is predicted quite well from a regression equation containing seven standardized regression weights of about the same order of magnitude and a larger weight for B \& $O$ XII. P3 involves $B$ \& $O$ VIII, VII, and III. P4 is most strongly influenced by $B$ \& $O$ I and VII, with lesser contributions from III and XII. The equation for predicting $P 5$ has the greatest weight associated with B \& $O$ III. Thus, B \& $O$ measures other than the five primary ones are necessary for predicting the dimensions of the average perceptual space.

Analysis of the Sorting Data

The Ss had no difficulty performing the sorting task, and no $S$ took longer than $5 \mathrm{~min}$ to complete the actual sorting. The number of categories used varied from 2 to 8 , with the mode of 5 categories being used by 15 Ss. The mean number of categories, taken over the $49 \mathrm{Ss}$, was 4.84 with a standard deviation of 1.55. Ss were given no instructions about what size the categories should be. Thirteen Ss achieved nearly uniform distributions of number of forms over categories. Two of these 13 formed 3 categories with 7 forms each. The other $36 \mathrm{Ss}$ had much greater discrepancies between the largest and smallest categories. Over all 49 Ss, the mean number of stimuli in the largest category was 6.88 , and in the smallest category, it was 3.02.

\section{On Scaling the Sorting Data}

A 21 by 21 (stimulus by stimulus) matrix was constructed with entries indicating how many $S 8$ had placed Stimuli $i$ and $j$ in the same category. The resultant matrix was symmetric with entries between 0 and 49 , inclusive, and having 49 in every cell on the main diagonal. Miller (1969) has suggested that the entries of a matrix such as this can be considered as judgments of interstimulus similarity given by the collection of $\mathrm{Ss}$. The more frequently two forms are judged to belong in the same category, the more similar they are assumed to be.

Table 6

Multiple Regresion Anaigde Predicting Peycholodical Dimencions of the Average Perceptual Space from the $B$ and $O$ Dimentions

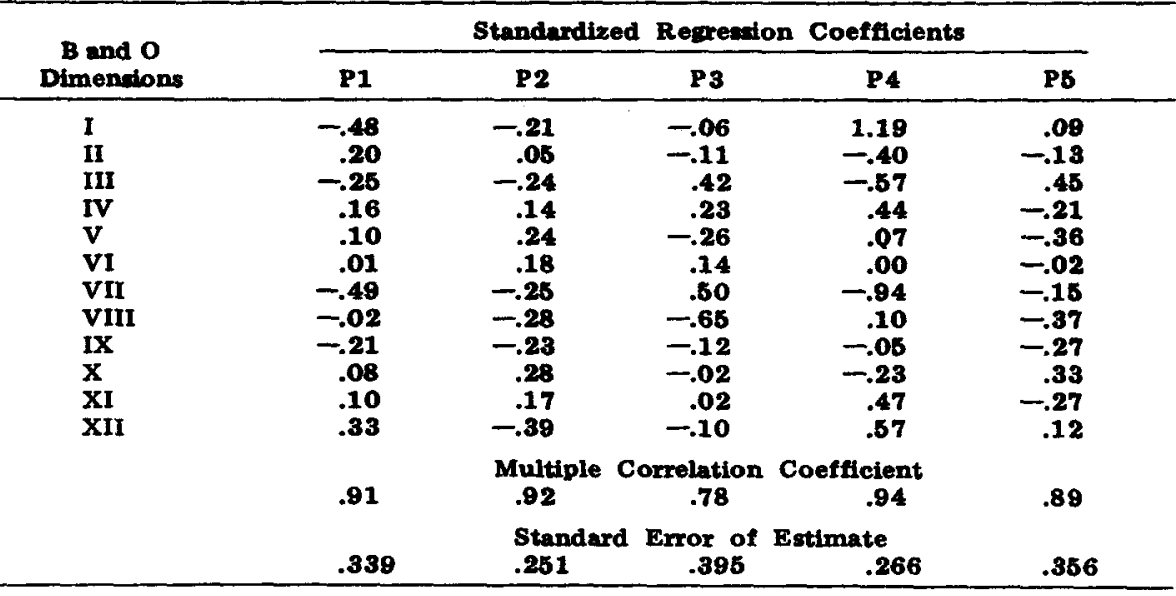


This co-occurrence matrix was input to the scaling programs in order to obtain a spatial model for the sorting data. More than 20 MDSCAL runs were performed to explore the $R=1.0$ and $R=2.0$ solutions which result from different starting configurations. The TORSCA program was also used with the sorting data. The MDSCAL $R$ - 2.0 runs from different starting configurations generally yielded the same minimum stress values at each of the several dimensionalities. However, the various MDSCAL $R=1.0$ runs falled to converge on the same minima. Generally, the $R=1.0$ streas values were higher than the corresponding $\mathbf{R}=\mathbf{2 . 0}$ stress values. But, when the euclidean solutions in five and six dimensions were used as starting configurations for the city block analyses, slightly lower stress values resulted for the corresponding $R=1.0$ solutions.

Table 7 contains the best stress various dimensionalities and metrics. The TORSCA stress and FIT values are also included, as well as Stenson and Knoll's lower bound. With this data, the TORSCA program failed to attain stress values as low as those found by MDSCAL. The kinds of considerations discussed earlier for the scaling data indicated that five or more dimensions were also necessary to account for the sorting data. A five-dimensional solution was sufficient if $R=2.0$, but an $R=1.0$ solution might involve either five or six dimensions.

The five-dimensional euclidean configuration is a model of perceptual judgments similar to that obtained from the average scaling data, except that it arises from a different task. This configuration was rotated to a Varimax solution. The initial and

Table 7

Best Stress Values for Sorting Data as Function of Metric and Dimensionality Bent streas Values for Soxting Data as a Suncti

\begin{tabular}{|c|c|c|c|c|c|c|}
\hline \multirow[b]{2}{*}{$\mathbf{R}=1.0$} & \multicolumn{6}{|c|}{ Dimensionality } \\
\hline & 1 & 2 & 3 & 4 & 5 & 6 \\
\hline $\begin{array}{c}\text { MDSCAL-Stress } \\
\text { TORSCA-Streas } \\
\text {-Fit }\end{array}$ & $\begin{array}{l}.283 \\
.317 \\
.974\end{array}$ & $\begin{array}{l}.154 \\
.182 \\
.992\end{array}$ & $\begin{array}{l}.114 \\
.132 \\
.996\end{array}$ & $\begin{array}{l}.071 \\
.096 \\
.998\end{array}$ & $\begin{array}{l}.040 \\
.079 \\
.998\end{array}$ & $\begin{array}{l}.025 \\
.060 \\
.999\end{array}$ \\
\hline \multicolumn{7}{|l|}{$\mathbf{R}=\mathbf{2 . 0}$} \\
\hline $\begin{array}{c}\text { MDSCAL-Stress } \\
\text { TORSCA-Stress } \\
\text {-Fit }\end{array}$ & $\begin{array}{l}.283 \\
.315 \\
.975\end{array}$ & $\begin{array}{l}.154 \\
.180 \\
.992\end{array}$ & $\begin{array}{l}.097 \\
.116 \\
.997\end{array}$ & $\begin{array}{l}.064 \\
.081 \\
.998\end{array}$ & $\begin{array}{l}.044 \\
.060 \\
.999\end{array}$ & $\begin{array}{l}.029 \\
.044 \\
.999\end{array}$ \\
\hline $\begin{array}{l}\text { Stenson and Knoll } \\
\text { Lower Bound }\end{array}$ & .46 & .27 & .17 & .15 & .09 & .07 \\
\hline
\end{tabular}
values for the sorting data over the

rotated models from the sorting task were then related to the physical characteristics of the stimuli and to the average perceptual spaces resulting from the scaling task.

\section{Relation to the}

Basic Physical Measures

Table 8 contains the correlations between the dimensions of the two models of the sorting task performance and the basic physical measures. These psychological dimensions will be called $P$ dimensions and $V$ dimensions, as with the models from the scaling task. P1 is size dispersion, having high correlations with $A$ and $P^{2} / A$. $P 3$ is angularity (VIA, MDIA, MSA, P2/A). P2 relates strongly to area (A). P4 has its strongest correlation with $P^{2} / A$ dispersion, and P5 combines dispersion and angularity. In the rotated configuration, V2 and V4 combine dispersion and angularity, with V2 having its highest correlation with $P^{2} / A$ and V4 being most correlated with MDIA. V1 is size dispersion, V3 is area, and V5 is most related to VDIA. The dimensions of these sorting spaces resemble those previously

Table 8

Correlations of the Reycholocied Dimentons of the Sorting Space With the Bade Phydical Mearures

Paycholocical Dimensions

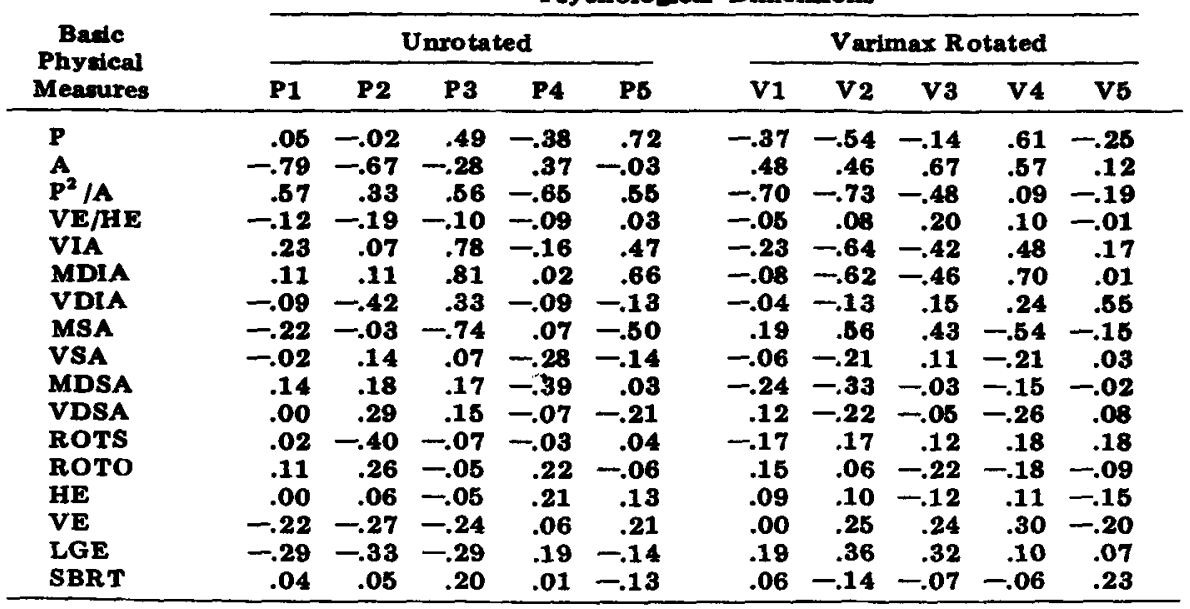

found in the average perceptual spaces from the scaling data. A comparison of Tables 4 and 8 reveals a high degree of similarity in the way the initial and rotated configurations from the two tasks relate to the basic physical measures.

\section{Correspondence with the}

Average Perceptual Space

Table 9 contains the simple correlations between the two initial (unrotated) psychological spaces. To facilitate the discussion of these relations, the various dimensions will be designated as belonging to the scaling (Sc) or sorting (So) space. A high correlation $(.87)$ exists between the P1 dimensions of the two spaces, and in both cases, this was said to be a size-dispersion dimension. $\mathrm{P2}$ (Sc) and P2 (So) correlate .68, and both involve area or size. P3 (So) correlates with both P2 (Sc) and P3 (Sc), and all are strongly related to the angle measures. The P4 dimensions from both configurations involve area and dispersion, and they correlate .66. P5 (So) and P5 (Sc) were both interpreted as dispersion dimensions with some influence of angularity, and they correlate .93.

A final examination of the correspondence between these two kinds of spatial models was conducted in terms of the canonical correlations between the two $P$ configurations. Table 9 also contains the results of this canonical analysis. Three very high canonical correlations were found $(.98, .96, .91)$. The standardized weights used in obtaining the canonical correlations are also shown in Table 9. There is obviously a high degree of correspondence between these two psychological spaces. Thus, in two kinds of tasks, highly similar spatial models were obtained from judgments of this group of $\mathrm{Ss}$ with respect to the 21 forms.

\section{$R=1.0$ Solutions \\ for the Sorting Data}

Stress values for the sorting data suggest that a five- or six-dimensional city block configuration might be 
Table 9

Correlations Between $\mathbf{P}$ Dimensions in $\mathbf{R}=\mathbf{2 . 0}$ Space from Sealing and Sorting Taks

\begin{tabular}{|c|c|c|c|c|c|c|}
\hline & & \multicolumn{5}{|c|}{ Scaling Dimensions } \\
\hline & & $\mathbf{P 1}_{1}$ & P2 & P3 & $\mathbf{P 4}$ & P5 \\
\hline $\begin{array}{l}\text { Sorting } \\
\text { Dimensions }\end{array}$ & $\begin{array}{l}\text { P1 } \\
\text { P2 } \\
\text { P3 } \\
\text { P4 } \\
\text { P5 }\end{array}$ & $\begin{array}{r}.87 \\
.41 \\
.30 \\
-.19 \\
.21\end{array}$ & $\begin{array}{r}.43 \\
.68 \\
.61 \\
-.42 \\
.26\end{array}$ & $\begin{array}{r}-.28 \\
-.20 \\
.58 \\
-.31 \\
.25\end{array}$ & $\begin{array}{r}-.19 \\
-.05 \\
.29 \\
.66 \\
.16\end{array}$ & $\begin{array}{r}.18 \\
.15 \\
.16 \\
-.23 \\
.93\end{array}$ \\
\hline
\end{tabular}

Canonical Analysis Relating Scaling and Sorting Configurations

\begin{tabular}{ccc} 
Variable & $\begin{array}{c}\text { Canonical } \\
\text { Correlation }\end{array}$ & $p<$ \\
\hline 1 & .978 & .0001 \\
2 & .860 & .0001 \\
3 & .906 & .0001 \\
4 & .834 & .0002 \\
5 & .465 & .0619
\end{tabular}

Standardized Weichts Associated With the Canonical Variables

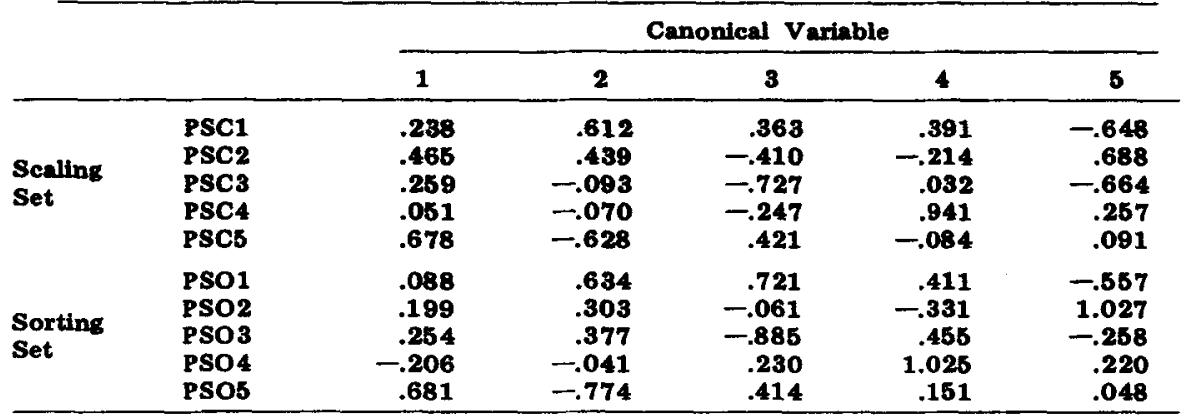

appropriate. Table 10 shows how the dimensions of these $R=1.0$ solutions relate to the basic physical measures. The five-dimensional solution contains a size-dispersion dimension (P1), an angularity dimension (P2), and a dispersion-angularity dimension (P5). P4 doesn't correlate with any of the physical measures, and P3 relates only marginally to VDIA. The six-dimensional solution has dimensions corresponding to the three interpretable ones from the five-dimensional solution. In addition, it contains a redundant size-dispersion dimension (P2), an area dimension (P4), and one uninterpretable dimension (P6).

These two $R=1.0$ solutions were obtained from the corresponding $R=$ 2.0 solutions. While a city block metric does reduce stress a little, these solutions are no more interpretable than the $R=2.0$ solutions. Furthermore, the spatial orientation of the $R=1.0$ solutions is unique; thus, they cannot be rotated into greater correspondence with the basic physical measures. In light of these considerations, the euclidean configurations were accepted as the best ones for this data.

\section{DISCUSSION Tasks}

All 49 of these Ss were involved in $4 \mathrm{~h}$ of perceptual experimentation and features for making judgments in the scaling task and then found it convenient to sort the forms on the basis of those features. Further work with the sorting task in the absence of prior scaling is therefore indicated.

The correspondence between the average perceptual space from the scaling data and the spatial model derived from the sorting data was, however, surprisingly good. The sorting data and the method of analysis employed here are potentially useful for exploring the kinds of common dimensions one obtains by scaling averaged judgments. The sorting and scaling tasks can provide the same kinds of outcomes if one is not concerned with $\mathbf{S}$ differences. The scaling task required about $2 \mathrm{~h}$ for each $S$ to accomplish, and a severely restricted set of stimuli had to be used. The sorting takk took only 5 min with the same number of stimuli. Large numbers of stimuli and $\mathrm{Se}$ can be ured in the sorting task quite economically. Since the set of stimuli used determines the number and kind of dimensions that are found, a task which permits the use of a large number of stimuli is preferable. If one is only interested in an average perceptual space or in a collection of potential cues, then the sorting task seems the reasonable one to use.

The refined data provided by the scaling task are appropriate for differentiating between $\mathbf{S s}$ and $\mathbf{S}$ types. Averaging this data over the set of Ss discards a good deal of information. A previous paper (Richards, 1972) examined individual differences in the scaling data reported here. Comparing the tables presented in this report with those in the previous one reveals that a more limited set of physical measures is important in the average perceptual space than in the spaces representing various $S$ types (idealized individuals). Only those physical measures which were related to the psychological spaces of several

Table 10

Correlations of the $R=1.0$ Poycholorical Dimengions from the Sorting Data With the Basic Physical Meamures

Peychological Dimentions

\begin{tabular}{|c|c|c|c|c|c|c|c|c|c|c|c|}
\hline \multirow{2}{*}{$\begin{array}{c}\text { Basic } \\
\text { Phydical } \\
\text { Measures }\end{array}$} & \multicolumn{6}{|c|}{ Six-Dimendional Solution } & \multicolumn{5}{|c|}{ Five-Dimensional Solution } \\
\hline & $\mathbf{P 1}$ & $\mathbf{P 2}$ & $\mathbf{P 3}$ & $\mathbf{P 4}$ & P5 & P6 & P1 & $\mathbf{P 2}$ & P3 & P4 & $\mathbf{P 5}$ \\
\hline $\begin{array}{l}\text { P } \\
\text { A } \\
\text { P }^{2} \text { /A } \\
\text { VIA } \\
\text { MDIA } \\
\text { VDIA } \\
\text { MSA } \\
\text { MDSA } \\
\text { VDSA } \\
\text { VE }\end{array}$ & $\begin{array}{r}.25 \\
-.76 \\
.70 \\
.26 \\
.21 \\
-.16 \\
-.23 \\
.18 \\
-.05 \\
-.07\end{array}$ & $\begin{array}{r}.33 \\
-.50 \\
.55 \\
.41 \\
.44 \\
-.09 \\
-.44 \\
.11 \\
.02 \\
-.46\end{array}$ & $\begin{array}{r}.31 \\
-.15 \\
.42 \\
.59 \\
.50 \\
.50 \\
-.56 \\
.12 \\
.01 \\
-.22\end{array}$ & $\begin{array}{r}.36 \\
.52 \\
-.01 \\
-.18 \\
-.06 \\
-.03 \\
.07 \\
-.11 \\
-.41 \\
.34\end{array}$ & $\begin{array}{r}.70 \\
.16 \\
.43 \\
.54 \\
.72 \\
.07 \\
-.62 \\
.14 \\
.01 \\
.13\end{array}$ & $\begin{array}{r}-.04 \\
.21 \\
-.30 \\
.20 \\
.45 \\
.00 \\
-.27 \\
-.40 \\
-.17 \\
.08\end{array}$ & $\begin{array}{r}.28 \\
-.79 \\
.76 \\
.24 \\
.16 \\
-.18 \\
-.20 \\
.26 \\
.02 \\
-.07\end{array}$ & $\begin{array}{r}.38 \\
-.33 \\
.49 \\
.54 \\
.60 \\
.08 \\
-.60 \\
.06 \\
-.20 \\
-.28\end{array}$ & $\begin{array}{r}.06 \\
-.24 \\
.29 \\
.42 \\
.19 \\
.49 \\
-.33 \\
.31 \\
.18 \\
-.36\end{array}$ & $\begin{array}{r}.35 \\
.28 \\
.18 \\
-.13 \\
-.19 \\
.03 \\
.13 \\
.17 \\
-.15 \\
.16\end{array}$ & $\begin{array}{r}.70 \\
.15 \\
.42 \\
.58 \\
.76 \\
.15 \\
-.58 \\
.10 \\
-.05 \\
.02\end{array}$ \\
\hline
\end{tabular}

Note-All measures for which no correlation exceeded 1.40 l were excluded from this table. 
idealized individuals were influential in the average perceptual space. In terms of cue utilization, the average perceptual space was quite distinct from each of the idealized individuals and could not be said to truly represent any of them.

\section{Psychologically Relevant} Measures

In line with the findings of previous investigators (Silver, Landis, \& Messick, 1965; Brown \& Andrews, 1968; Behrman \& Brown, 1968; Stenson, 1968), measures reflecting the dispersion and angularity of the forms were important correlates of the psychological dimensions isolated in this study. Separate dimensions showed different patterns of relation to $P, A$, and $P^{2} / A$, and thus separable aspects of size and dispersion cues. The important indices of angularity (VIA, MDIA, and MSA) also varied in their relations to different dimensions of the average perceptual space. Rotation as indexed by $B$ \& $O V$ was also important, although none of the four basic rotation measures (VE/HE, ROTO, SBRT, ROTS) were.

The Brown and Owen Measures In the present study, it was necessary to use the basic physical measures to interpret both the psychological dimensions and the $\mathrm{B} \& \mathrm{O}$ measures. While some strong relations of $B \& \mathbf{O}$ measures to psychological dimensions were found, the meaning of those correlations had to be examined using the basic physical measures. The B \& 0 dimensions will be useful for interpretation only when they are more fully understood. Brown and Owen have offered interpretations for only the first five of their dimensions, but some of the others appear to be quite important in their relation to perceptual judgments.

The Brown and Owen measure space is potentially valuable because
(1) it is based on a large sample of forms and form measures, and (2) it provides a set of summary dimensions which are orthogonal in the population. As a set of "predictors," the $B$ \& $O$ dimensions, being orthogonal, are more useful than the basic physical measures which display many redundancies. The $B \& O$ measures also provide useful standards for comparing relative cue utilization across samples of Ss and stimuli. They comprise an efficient characterization of a given set of forms in terms of a mathematically simple and tractable model.

However, the $\mathrm{B} \& \mathrm{O}$ measures are presently limited in utility because they are restricted to the stimulus sets investigated by Brown and Owen. An investigator with a form or set of forms of interest to him cannot obtain the values of that form on the $B \& O$ measures without essentially repeating the entire procedure followed by Brown and Owen. Unless one is content to use only those forms in Brown's collection, direct ways of obtaining the B \& $O$ measures must be developed. If such direct measures are not forthcoming, selected basic physical measures will continue to be preferred by those who study form perception. Of course, the choice of an optimal set of basic physical measures might be dictated by the relation of that set to the $B$ \& $O$ measures.

\section{REFERENCES}

ATTNEAVE, F. Physical determinants of the judged complexity of shapes. Journal of Experimental Psychology, 1957, 53, :21-227.

ATTNEAVE, F., \& ARNOULT, $M$. D. The quantitative study of shape and pattern perception. Psychological Bulletin, 1956, $53,452-471$.

BEHRMAN, B. W., \& BROWN, D. R. Multidimensional scaling of form: A psychophysical analysis. Perception \& Psychophysics, 1968, 4, 19-25.
BROWN, D. R., \& ANDREWS, M. H. Visual form discrimination: Multidimensional analyses. Perception \& Psychophysics, $1968,3,401-406$.

BROWN, D. R., \& OWEN, D. H. The metrics of visual form: Methodological dyspepsia. Psychological Bulletin, 1967 68, 243-259.

KRUSKAL, J. B. Multidimensional scaling by optimizing goodness of fit to a nonmetric-hypothesis. Psychometrika, 1964a, 29, 1-28.

KRUSKAL, J. B. Nonmetric multidimensional scaling: A numerical method. Psychometrika, 1964b, 29, 115-130.

MILLER, G. A. A psychological method to investigate verbal concepts. Journal of Mathematical Psychology, 1969, 6. 169-191.

RICHARDS, L. G. A multidimensional scaling analysis of perceived similarity among complex forms. Unpublished manuscript, University of Virginia, 1971

RICHARDS, L. G. An analysis of individual differences in similarity judgments about complex random forms. Perception \& Psychophysics, 1972, 11, 143-149.

SILVER, C. A., LANDIS, D., \& MESSICK, S. J. Multidimensional analysis of visual form: An analysis of individual differences. American Journal of Psychology, 1966, 74, 62-72.

SHEPARD, $R$. N. The analysis of proximities: Multidimensional scaling with an unknown distance function: $I$. Psychometrika, 1962a, 27, 125-140.

SHEPARD, R. N. The analysis of proximities: Multidimensional scaling with an unknown distance function: II. Psy chometrika, 1962b, 27, 219-246.

STENSON, H. H. The physical factor structure of random forms and their judged complexity. Perception \& Psy chophysics, 1966, 1, 303-310.

STENSON, H. H. The psychophysical dimensions of similarity among random shapes. Perception \& Psychophysics, $1968,3,201-214$

STENSON, H. H., \& KNOLL, R. I. Goodness of fit for random rankings in Kruskal's nonmetric scaling procedure. Psychological Bulletin, 1969, 71 . 122-126.

TORGERSON, w. S., \& MEUSER, G. Informal notes on Torgerson and Meuser's IBM 7090 program for multidimensional scaling. Johns Hopkins University, mimeographed report, 1962.

YOUNG, F. W. A FORTRAN IV program for nonmetric multidimensional scaling. The L. L. Thurstone Psychometric Laboratory, University of North Carolina. Report No. 56, 1968.

(Accepted for publication April 25, 1972.) 